\title{
Energy and Exergy Analysis of a Vegetable Oil Refinery
}

\author{
Musediq Adedoyin Sulaiman ${ }^{1}$, Abayomi Olufemi Oni ${ }^{2}$, David Abimbola Fadare ${ }^{3}$ \\ ${ }^{1}$ Mechanical Engineering Department, Olabisi Onabanjo University, Ago-Iwoye, Nigeria \\ ${ }^{2}$ Mechanical Engineering Department, University of Agriculture Abeokuta, Abeokuta, Nigeria \\ ${ }^{3}$ Mechanical Engineering Department, University of Ibadan, Ibadan, Nigeria \\ Email: fadareda@gmail.com
}

Received June 18, 2012; revised July 20, 2012; accepted August 2, 2012

\begin{abstract}
Energy and exergy analysis was conducted for a vegetable oil refinery in the Southwest of Nigeria. The plant, powered by two boilers and a $500 \mathrm{kVA}$ generator, refines 100 tonnes of crude palm kernel oil (CPKO) into edible vegetable oil per day. The production system consists of four main group operations: neutralizer, bleacher, filter, and deodorizer. The performance of the plant was evaluated by considering energy and exergy losses of each unit operation of the production process. The energy intensity for processing 100 tonnes of palm kennel oil into edible oil was estimated as 487.04 $\mathrm{MJ} /$ tonne with electrical energy accounting for $4.65 \%$, thermal energy, $95.23 \%$ and manual energy, $0.12 \%$. The most energy intensive group operation was the deodorizer accounting for $56.26 \%$ of the net energy input. The calculated exergy efficiency of the plant is $38.6 \%$ with a total exergy loss of 29,919 MJ. Consequently, the exergy analysis revealed that the deodorizer is the most inefficient group operation accounting for $52.41 \%$ of the losses in the production processes. Furthermore, a critical look at the different component of the plant revealed that the boilers are the most inefficient units accounting for $69.7 \%$ of the overall losses. Other critical points of exergy losses of the plant were also identified. The increase in the total capacity of the plant was suggested in order to reduce the heating load of the boilers. Furthermore, the implementation of appropriate process heat integration can also help to improve the energy efficiency of the system. The suggestion may help the company to reduce its high expenditure on energy and thus improve the profit margin.
\end{abstract}

Keywords: Vegetable Oil Refining; Crude Palm Kernel Oil; Energy; Exergy; Irreversibility

\section{Introduction}

The production of edible oil has been in practice in Nigeria for centuries, and it remains an essential ingredient in much of the southwest of the country cuisine. It uses are also found in animal feed, for medicinal purposes, and for certain technical applications. Its enormous demand for various purposes has made the industry very important. According to the vegetable oil producers, Nigeria is selfsuficient in edible oil requirement. Statistics show that the country produces altogether 500,000 metric tonnes of edible oil annually made up of 320,000 metric tonnes from the organized sector while the remaining 180,000 metric tonnes come from small-scale producers in the unorganized sector [1]. Total demand of refined edible oil in Nigeria is put at 250,000 metric tonnes annually [1]. By this statistics, the country is supposed to export about 250,000 metric tonnes of edible oil to neighboring West African countries annually. The vegetable oil industry has played a significant role in the national economy generating business worth more than 10 billion naira for transportation and allied sectors. It has provided over 25,000 direct employments and indirect employment for more than one million farming families. Altogether, the industry is believed to have direct effect on the lives of more than six million Nigerians [1]. However, the Nigerian edible oil refineries are facing more challenges today than ever before as a result of increased competitiveness and varying energy demand. In addition, high cost of production, the epileptic supply of electrical energy supply from the national grid, inadequate production and distribution of petroleum products and the growing concern over global warming have created complex and sometimes conflicting challenges for industrial operations. The industries must operate a system that runs effectively in order to survive in today's highly competitive world market. Hence, the Nigerian industries are seeking cost effective energy saving technology and practices that will minimize energy use while maintaining or increasing product quality and quantity.

The possibilities of minimizing energy wastage in production processes cannot be overemphasized. This necessitate the need to investigate the useful part of energy, in any particular section on the production line, which economically helps save cost of production and automatically improves the reduction in the energy wastage. This fact therefore sets in the effective and efficient use of energy 
which is very important to industries. As much as energy is highly important for the process industries, minimum amount of energy should be wasted under normal situations.

The traditional method of assessing the energy disposition of an operation involves the application of first law of thermodynamic. The advent of exergy method which is based on the second law of thermodynamic exposes the inadequacies of the first law. Exergy analysis provides information about the irreversibility state of thermodynamic processes. It thus indicates means of assessing the locations, types and magnitudes of wastes and losses and to identify meaningful efficiencies of the system. The wide spread of the use of exergy method by several researcher has brought about steps towards cutting down on energy cost, conservation of scarce energy resources and reduction of environmental damage. Exergy analysis methodologies have been applied to many industrial systems such as: sugarcane bagasse gasification [2], malt drink production [3], flavored yogurt [4], and fruit juice [5]. Although a considerable volume of energy and exergy-related analyses of industrial processes exists in literature, limited work has been reported on energy and exergy analyses of vegetable oil from palm kennel oil processing operations. Energy and exergy analysis for production of vegetable oil from soybean oil, sunflower and olive oil has been reported for Turkey. Only the work of Fadare et al. [2] and Waheed et al. [5] has respectively reported the energy and exergy analyses of malt drink and fruit juice processing operations in Nigeria. To the best of the authors' knowledge, no work has been conducted on the energy and exergy analyses of edible vegetable oil production in Nigeria. Therefore, the aim of this study is to analyze the energy consumption pattern and exergy inefficiency of palm kennel oil refining operations in Nigeria, in view of improving the efficiency of the system, reduce the production costs and hence, increase the profitability of edible vegetable oil production.

\section{Materials and Method}

\subsection{Plant Description}

Energy and exergy studies of refining crude palm kennel oil into edible vegetable oil were conducted in a factory located in the southwestern Nigeria. The energy requirement and exergy inefficiency for processing 100 tonnes per day of edible vegetable oil from palm kernel oil was estimated. The plant operates on a 3-shift of 8-working hours per day with a total of 55 workers per shift out of which about 27 workers are involved in the production process due to the automation level of the factory. The main sources of energy utility for the plant are electrical, thermal and manual. The primary source of electrical energy used is either from the national grid or from the company's power generating set. Steam generated from diesel-fueled boilers is used for heating purpose, while cooling is effected through the use of condensers.

\subsection{Process Description}

The production steps consist of four group operations: neutralizer, bleacher, filter, and deodorizer, which are powered with two boilers for steam generation and a $500 \mathrm{kVA}$ generator for electricity generation. The process flow line for processing of edible vegetable oil from palm kennel oil is shown in Figure 1. The crude oil (palm kernel oil) is kept under vacuum in a buffer feed tank. The oil is first pumped through a heat exchanger, where it is heated by the outgoing hot deodorized oil. Phosphorus acid solution is pumped with the aid of dosing pump into the static acid mixer and is mixed with the crude oil. The mixture is then routed to the neutralizer. The purpose of neutralization is to change the structure of gums or phosphatides present

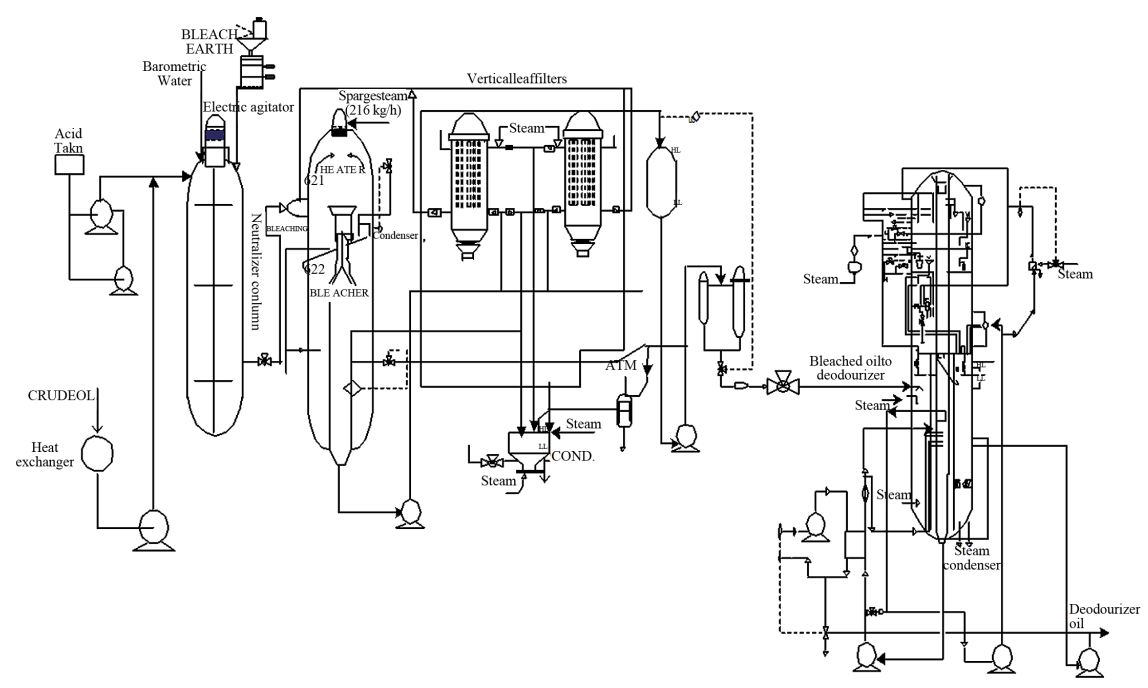

Figure 1. Schematic diagram of the production of edible vegetable oil. 
in the crude oil in such a way that they can be removed during the bleaching process. The required amount of bleaching earth is added in the tank by the bleaching earth dosing device. Under atmospheric pressure, the oil is pushed into the bleacher. The neutralized oil is treated with bleaching earth/activated carbon for the removal of colouring pigments. The mixture is then heated by steam while the contents are maintained under vacuum by the barometric condenser and vacuum pump. When the required temperature is reached, the moisture present in the oil is completely removed upon completion of bleaching. This oil-bleached suspension is routed to the hermetic leaf filters where bleaching earth and precipitated matters are removed. Deodorization is the last stage in the vegetable oil refining process. The operation is carried out at high temperature by injecting open stream and maintaining high vacuum at which time all the odiferous matter is distilled off and carried away to barometric condensers through vacuum system. Under reduced pressure, volatile free fatty acids and other substances are also removed in order to produce bland final product. The result is odourless product with an acceptable, colour and taste. The bland oil is then sent to final storage with the addition of oxidants to prolong the product shelf life.

\subsection{Data Collection}

The plant utilized electrical, thermal and manual energies for the production process. The required parameters for evaluating energy consumption and exergy efficiency in each unit operation were measured directly or obtained from the factory's energy department. An inventory of the power rating of electric motors, properties of steam, coolant and product streams, boiler and chiller operating conditions, number of man-power required for manual labour and time taken for each operation were determined. The data were collected from the plant over a period of two months. The measuring quantities used in the course of the data acquisition include: 1) A stopwatch for measuring the time spent in each operation; 2) A measuring cylinder for measuring the amount of fuel consumed and 3) A weight balance for measuring the quantity of crude and processed oil.

\subsubsection{Evaluation of Electrical Energy}

The electrical energy input, $E_{p}$, in $\mathrm{kW}$ h was obtained by multiplying the rated power of the electric motor, $P$, in $\mathrm{kW}$ with the corresponding hours of operation, $t$. The motor efficiency, $\eta$, was assumed to be, $80 \%$ [2]:

$$
E_{P}=\eta P t
$$

\subsubsection{Evaluation of Thermal Energy}

Thermal energy input, $E_{F}$, was calculated based on quantity of fuel (diesel or oil-cake) used to generate steam in the boiler. The quantity of fuel, $\mathrm{W}$, in kg used was converted to energy (MJ) by multiplying the quantity consumed by the corresponding calorific value, $C_{f}$, of fuel $(\mathrm{J} / \mathrm{kg})[2]$ :

$$
E_{F}=C_{f} W
$$

Note that the calorific value for diesel and oil-cake are respectively 42 and $37 \mathrm{MJ} / \mathrm{kg}$ [2].

\subsubsection{Evaluation of Manual Energy}

Manual energy, $E_{m}$, in $\mathrm{kW}$ was estimated based on the value recommended by Odigboh [5]. According to him, at maximum continuous energy consumption rate of $0.30 \mathrm{~kW}$ and conversion efficiency of $25 \%$, the physical power output of a normal human labour in tropical climates is approximately $0.075 \mathrm{~kW}$ sustained for an 8 - 10 hour workday:

$$
E_{m}=0.075 N t(\mathrm{~kW} \cdot \mathrm{h})
$$

$N$ is the number of persons involved in the operation and $t$ is the useful time spent to accomplish a given task in hours.

\subsubsection{Evaluation of Energy Intensity}

Energy intensity is the amount of the energy required per unit output of the production. Production volumes in this case are expressed in tonnes. The energy intensity was evaluated as the ratio of total energy input, $E_{T}$, in MJ and the volume of edible vegetable oil produced, $V_{t}$ in tonnes:

$$
E_{i}=\frac{E_{T}}{V_{t}}
$$

The required parameters for evaluating energy and exergy in the four unit operations are represented in Table 1.

\subsection{Exergy Change of the Process Stream}

The exergy of process stream $\left(E_{x}\right)$ can be expressed as the sum of the physical $\left(E_{P H}\right)$, chemical $\left(E_{C H}\right)$, kinetic $\left(E_{K}\right)$ and potential $\left(E_{P T}\right)$ exergy. Mathematically,

$$
E_{x}=E_{P H}+E_{C H}+E_{K}+E_{P T}
$$

where

$$
\begin{gathered}
E_{P H}=\left(h-h_{0}\right)-T_{0}\left(s-s_{0}\right) \\
E_{P T}=m g h \\
E_{K}=\frac{m v^{2}}{2} \\
E_{C H}=\sum_{i} \mu_{0, i} N_{i}
\end{gathered}
$$

where $\mu_{0, i}=h_{0, i}-T_{0, i} S_{0, i}$ and $N_{0, i}=$ number of moles. 
Table 1. Required parameters for evaluating energy and exergy values in the refining of palm kennel oil.

\begin{tabular}{|c|c|c|}
\hline Unit operation & Required parameters & Value \\
\hline \multirow[t]{6}{*}{ Neutralization } & Number of persons & 4 \\
\hline & Time taken (h) & 5 \\
\hline & Electrical power $(\mathrm{kW})$ & 37 \\
\hline & Crude oil inlet temperature (K) & 303 \\
\hline & Crude oil outlet temperature (K) & 358 \\
\hline & Weight fraction of water in oil & 0.03 \\
\hline \multirow[t]{8}{*}{ Bleaching } & Number of persons & 7 \\
\hline & Time taken (h) & 6 \\
\hline & Electrical power $(\mathrm{kW})$ & 5.5 \\
\hline & Neutralized oil inlet temperature (K) & 358 \\
\hline & Neutralized oil outlet temperature (K) & 373 \\
\hline & Steam mass requirement $(\mathrm{kg} / \mathrm{h})$ & 215 \\
\hline & Density of neutralized oil (kg/l) & 0.9 \\
\hline & Weight fraction of water in oil & 0.04 \\
\hline \multirow[t]{6}{*}{ Filtration } & Number of persons & 2 \\
\hline & Time taken (h) & 5 \\
\hline & Electrical power $(\mathrm{kW})$ & 5.5 \\
\hline & Bleached oil inlet temperature (K) & 373 \\
\hline & Bleached oil outlet temperature (K) & 353 \\
\hline & Weight fraction of water in oil & 0.04 \\
\hline \multirow[t]{8}{*}{ Deodorizing } & Number of persons & 7 \\
\hline & Time Taken (h) & 7 \\
\hline & Electrical power $(\mathrm{kW})$ & 26.2 \\
\hline & Steam mass requirement $(\mathrm{kg} / \mathrm{h})$ & 513 \\
\hline & Filtered oil inlet temperature (K) & 353 \\
\hline & Deodorized oil outlet Temperature (K) & 473 \\
\hline & Density of oil (kg/l) & 0.85 \\
\hline & Weight fraction of water in oil & 0.06 \\
\hline
\end{tabular}

In Equations (6)-(9) $h$ is the specific enthalpy (kJ/kg), $s$ is the specific entropy $(\mathrm{kJ} / \mathrm{kg} \cdot \mathrm{K})$, both evaluated at $T$ and $P$ of each process stream; $h_{0}$ and $s_{0}$ are, respectively, the specific enthalpy and specific entropy evaluated at the reference state $\left(T_{0}=298.15 \mathrm{~K}\right.$ and $\left.P_{0}=100 \mathrm{kP}\right)$.

For a typical control volume with steady flow and accumulation of exergy occurring in the system, the exergy balance of the system can be represented as [6]:

$$
\sum_{j}\left(1-\frac{T_{0}}{T_{j}}\right) \dot{Q}_{j}-\dot{W}_{c v}+\sum_{i} \dot{m}_{i} e_{i}-\sum_{0} \dot{m}_{i} e_{i}-I_{c v}=0
$$

The term $Q$ represents the time rate of heat transfer across the boundary, $T_{j}$ is the instantaneous temperature of the boundary, $W_{C V}$ is the time rate of exergy transfer by work, $I$ is the time rate of exergy loss due to irreversibility within the system, the term $m_{i} e_{i}$ accounts for the time rate of exergy transfer accompanying mass flow and flow work, while subscripts $i$ and $o$ represents the inlet and outlet, respectively.

The specific flow exergy $(e)$ of the system can be expressed as:

$$
e=h-h_{0}-T_{0}\left(S-S_{0}\right)+\frac{V^{2}}{2}+g z
$$

where $h$ and $s$ denote the enthalpy and entropy of the system respectively, $h_{0}, s_{0}$ and $T_{0}$ are the enthalpy, entropy, and temperature, respectively at the dead state (environment).

Neglecting the kinetic and potential energy, the net change of exergy of the system can be expressed as:

$$
e_{2}-e_{1}=h_{2}-h_{1}-T_{0}\left(S_{2}-S_{1}\right)
$$

The net exergy change of the process stream in and out of each unit operation in the edible vegetable oil production system was evaluated using the predictive model proposed by Singh [7]:

$$
e_{2}-e_{1}=c_{p}\left(T_{2}-T_{1}\right)\left[1-\frac{T_{0}}{\left(T_{2}-T_{1}\right) m l}\right]
$$

where

$$
\left(T_{2}-T_{1}\right) m l=\frac{T_{2}-T_{1}}{\ln \left(T_{2} / T_{1}\right)}
$$

The specific heat capacity of the edible vegetable oil can be determined using the expression

$$
c_{p}=4.1868(0.3823+0.6183 x)
$$

where $x$ is the weight fraction of water in the oil.

\subsection{Exergy Inefficiency and Useful Work of the System}

The exergy inefficiency can be evaluated with the expression

$$
I_{f f}=\frac{I}{\sum I_{\text {all }}}
$$

where $I_{\text {ff }}$ is the inefficiency of the system and is defined as the ratio of the irreversibility in each unit operation to the irreversibility in the overall operations.

The useful work input into the system can be expressed as [7]:

$$
W_{u}=\left(e_{2}-e_{1}\right)-T_{0} R_{s}
$$

where $W_{u}$ is the useful work, $R_{S}$ the production of entropy and $T_{0}$ the ambient temperature. The exergy difference $e_{2}-e_{1}$ is defined in terms of each component exergy $e_{x}$ per unit mass and the mass flow rate $m$. From Equation 
(14), it is obvious that the exergy change is a balance of useful work and the entropy production term, which can be regarded as work loss because of irreversibilities.

\subsection{Exergy Efficiency}

In order to determine how well the desired effect of the system is accomplished, the efficiency is calculated as the ratio of the net produced exergy to the net supplied exergy or as a fraction of the net supplied exergy used by the system to perform its function [8]:

$$
\eta=1-\left(\frac{I_{\text {loss }}}{e_{\text {in }}}\right)
$$

\section{Results and Discussion}

\subsection{Energy Expenditure of the Plant}

A total of $23 \mathrm{~h}$ was required to process a batch of 100 tonnes of palm kennel oil in edible vegetable oil. For this case, there was a total outage of electricity supply from national grid, hence the power generating set was used for the entire production process. The average rate of fuel consumption by the power generating set (diesel), boiler 1 (oil cake), and boiler 2 (diesel) are respectively 21.0, 45.7 and $56.3 \mathrm{~kg} / \mathrm{h}$. The total energy consumption for the entire production was therefore, estimated to be 48,703 MJ while the average energy intensity was $487.0 \mathrm{MJ} /$ tonne.

The energy consumption pattern for the main group operations is shown in Table 2. The net energy input into the production units was estimated as 23333.64 MJ with thermal (95.23\%), electrical (4.65\%) and manual (0.12\%) of the energy input. The deodorizing operation consumed the highest energy with $13127.96 \mathrm{MJ}$ (52.26\%), followed by the bleaching process with 9224.21 MJ (39.53\%), neutralization unit with $899.18 \mathrm{MJ}$ (3.85\%) while the filtration operation accounted for the least energy with 81.9 MJ (0.35\%).

\subsection{Exergy Expenditure of the Plant}

The exergy analysis of the system gave insight to the inefficiencies and the opportunities for exergy loss minimization of each of the unit operations in the four main group operations involved in the production of palm kennel oil. Conceptually the exergy calculation of the system was divided into process stream exergy and utility exergy. Exergy accounts for individual process were presented in order to identify major losses and evaluate the potential for further technical improvements in the production of the palm kennel oil processes.

The exergy expenditure of the plant was divided into two main categories. The first evaluation looks into the four main group operations while the second category examines the exergy losses in all the plant components including the utility sections (boiler 1 and 2). In the first category, the exergy change in process stream, useful work, steam exergy (utilities), entropy generated, effluent losses and the inefficiency associated with the different unit operations in the overall production system was evaluated. The change in the oil exergy was only associated with operations where there was change in the inlet and outlet temperatures. This can be seen to occur in all the unit operations considered. The negative value of exergy change in the filtration unit was due to the drop in temperature of the oil during the process. Furthermore, the useful work comprised both electrical and manual energy (Table 3).

Table 2. Time and energy use data in refining of palm kernel oil.

\begin{tabular}{ccccccc}
\hline Unit operation & Time taken $(\mathrm{h})$ & Electrical energy, $E_{t}(\mathrm{MJ})$ & Thermal energy, $E_{t}(\mathrm{MJ})$ Manual energy, $E_{m}(\mathrm{MJ})$ & Total energy, $E_{o}(\mathrm{MJ})$ & $E_{o} / E_{t t}(\%)$ \\
\hline Neutralization & 5 & 532.8 & 361 & 5.4 & 11.34 & 899.18 \\
Bleaching & 6 & 95.04 & 9118.23 & 2.7 & 9224.61 & 39.85 \\
Filtration & 5 & 79.2 & - & 9.45 & 81.90 & 0.35 \\
Deodorizing & 7 & 377.28 & 12741.23 & 28.89 & 13127.96 & 56.26 \\
Total & 23 & 1084.32 & 22220.43 & & 23333.64 & 100 \\
\hline
\end{tabular}

Table 3. Exergy balance in the edible vegetable processing operation.

\begin{tabular}{|c|c|c|c|c|c|c|c|}
\hline Components & $\begin{array}{l}\text { Exergy change } \\
\text { (MJ) }\end{array}$ & $\begin{array}{l}\text { Useful work } \\
\text { (MJ) }\end{array}$ & $\begin{array}{l}\text { Utilities/process stream } \\
\text { exergy change (MJ) }\end{array}$ & $\begin{array}{l}\text { Irreversibility } \\
\text { (MJ) }\end{array}$ & $\begin{array}{l}\text { Effluent losses } \\
\text { (MJ) }\end{array}$ & $\begin{array}{l}\text { Total exergy } \\
\text { losses (MJ) }\end{array}$ & Inefficiency (\%) \\
\hline Neutralization & 193 & 538.2 & 360.98 & 706 & & 706 & 7.79 \\
\hline Bleaching & 124 & 106.38 & 2916 & 2898 & 475 & 3373 & 37.21 \\
\hline Filtration & -157 & 81.9 & 0 & 239 & & 239 & 2.63 \\
\hline Deodorizer & 1687 & 386.73 & 2915 & 1615 & 3132 & 4747 & 52.37 \\
\hline Total & 1847 & 4715 & 6191 & 5457 & 3607 & 9065 & 100 \\
\hline
\end{tabular}


The electrical energy is an energy source that consists of pure exergy while the inability to account for the entropy generated by a human labourer justified its inclusion in the useful work [3]. The results obtained for the different unit operations are presented in Table 4. An overall evaluation of the production processes from an exergy perspective reveals the ranking of order of the energy killers in the plant. From this stand point, the highest entropy was generated in the deodorizer (accounting for more than half of the losses) followed by bleaching, neutralizer and filtration. The irreversibilities within the systems are as a result of high temperature difference between the inlet and the outlet stream of both the oil streams, heating and cooling utilities. From the technical analysis of the different component, a considerable part of the losses in the deodorizer can be attributed to wasteful energy losses during heating and cooling respectively. Of the total exergy losses in the deodorizer, the deodorizer column accounted for 34 percent while deodorizer steam condensers accounted for 66 percent. This is an indication that the heating and cooling resulted into wasteful losses. This is always the case for exergy calculations and is due to the fact that the exergy value of heat is often much lower than its energy value, particularly at temperatures close to reference temperature Fadare et al. [3]. The irreversible and effluent losses are minimal in other units.

In the second category, a holistic overview of the entire component (boilers included) was considered. The exergy efficiencies along with the percentage of exergy losses are summarized in Table 5 for all components present in the plant. It is obviously that the exergy losses rate of the boiler is dominant over all other losses in the plant. The boilers accounts alone for $69.7 \%$ of losses in the plant, while the exergy destruction rate of the deodorizer is only $10.47 \%$. The inefficiency in the boilers unit was an indication of significant losses due to high entropy generation at conditions at which the unit operates. At these conditions, the irreversibility of the combustion reaction occurring in the combustion cham-

Table 4. Exergy efficiencies and percentage losses of the plant component.

\begin{tabular}{ccc}
\hline Component & Exergy efficiency \% & Percentage losses \\
\hline Neutralization & 53.5 & 2.36 \\
Bleaching column & 4.3 & 9.69 \\
Bleaching condenser & - & 1.59 \\
Filtration & - & 0.80 \\
Deodorizer column & 57.9 & 5.40 \\
Deodorizer condenser & & 10.47 \\
Boiler 1 & 23.9 & 30.12 \\
Boiler 2 & 30.0 & 39.58 \\
\hline
\end{tabular}

Table 5. Energy intensity data from various literatures.

\begin{tabular}{ccc}
\hline Process & $\begin{array}{c}\text { Energy intensities } \\
\text { (MJ/tonne) }\end{array}$ & Reference \\
\hline Pelletized organic fertilizer production & 350.0000 & {$[9]$} \\
Powdered organic fertilizer production & 280.0000 & {$[9]$} \\
Fruit juice production & 0.0011 & {$[5]$} \\
Olive oil production & 10028.6000 & {$[10]$} \\
Sunflower oil production & 7795.4000 & {$[10]$} \\
Soya bean oil production & 7619.1000 & {$[10]$} \\
Palm kennel oil & 487.0379 & Present work \\
\hline
\end{tabular}

bers of the boilers increases, hence relatively low exergy efficiencies of the boilers is exhibited. Although, the bleaching column has a low exergy efficiency and a relatively low exergy lose, this situation arise because exergy efficiency values are quantitative measurement derived as a ratio of two numbers with the constraint that the ratio is not greater than one, whereas exergy losses are quantitative measurements derived as the difference between two numbers. Exergy efficiency was not defined for the condensers [11] and filters this is because the purpose of these devices is to reject waste heat rather than generate product. The calculated exergy efficiency of the palm kennel oil plant was found to be $38.6 \%$, which is low. This indicates that tremendous opportunities are available for improvement. However, part of this irreversibility cannot be avoided due to physical, technological, and economic constraints.

The avoidable losses of the plant can be reduced by increasing the capacity of the plant which will result in the reduction of the load on the boiler following similar suggestion made by Dalsgard [12]. Also, the utilization of cooling and heating utilities can be reduced if the appropriate heat integration method is in place. The purpose of heat integration in this case is to identify all unmatched existing hot and cold streams. A composite line are drawn which provide a way to match them in an optimum fashion with respect to energy. The matching lines has precise counterpart in terms of exergy balance [13]. This will enable a longer production time and thus reduce avoidable energy wastage and the corresponding exergy destruction that will occur by plant start-up, shutdown, cleaning and sterilization. If this suggestion is taken, it may help the company to reduce its high expenditure on energy and thus improve the profit margin.

\subsection{Comparison of the Energy Intensities and Exergy Inefficiencies in the Production of Edible Vegetable Oil from Palm Kennel Oil}

The trend in energy utilization for the processing of edible vegetable oil from palm kennel oil has not been reported however effort is made by comparing this study 
with edible vegetable oil from soybean oil, sunflower, olive oil and other non-vegetable oil production processes found in literature.

The energy intensities reported in this study is lower as compared to the production of vegetable oil from soybean oil, sunflower oil and olive oil [10] (Table 5). This can be attributed to varying factors such as the differences in inherent energy requirement of the production steps of the different products reported and the extent of the system boundary of the analysis. However, the result was higher than values found in other production processes such as organic fertilizer [9] and fruit juice production [5]. An indication that the production of edible oil from palm kennel oil is more energy intensive than this processes.

The exergy inefficiency in the production of the aforementioned vegetables oil (soybean oil, sunflower oil and olive oil) was not reported therefore comparison was not possible. Although, comparison with other works was also difficult due to lack of similar process, however, the present work can further be illustrated by comparing the pasteurizer inefficiency found by Fadare et al. [2] as $59.75 \%$, and evaporator inefficiency reported by Rotstein [13] as $68 \%$ with the deodorizer inefficiency presented in this study which is $52.4 \%$. All the processes considered are the point of highest inefficiencies in the main production steps from the literature and present work.

\section{Conclusions}

The energy and exergy consumption for production of 100 tonne of edible vegetable oil were estimated for a Nigerian palm kennel oil refining industry. Four defined group operations were identified in the production steps: neutralizer, bleaching, filtration and deodorizer. The energy audit revealed that the types of energy input for the production were electrical (4.65\%), thermal (95.23\%) and manual $(0.12 \%)$ of the net energy input. The average energy intensity of the process was estimated as 487.04 $\mathrm{MJ} / \mathrm{kg}$. The deodorization unit was the most energy intensive process with $13127.96 \mathrm{MJ}$ accounting for $52.4 \%$ of the net energy input the production. The company depended mainly on the use diesel and de-oils cake to power the steam boilers and diesel for the company's power generating set for supply of electrical power. The use of diesel in Nigeria is not cost effective [3] therefore the use of filtered cake of spent bleaching earth (de-oil cake) should be encouraged for the generation of steam in oil production processes.

An exergetic insight into the different unit operations reveals the amount of entropy generated and effluent losses associated in the operations. It can be seen that each section or unit of the plant is characterized by a certain level of entropy production. Considering the main group operation, exergy loss is highest in the deodorizer accounting for over half of the exergy losses in the production line while boiler 2 is the most inefficient component accounting for $39.6 \%$ of the overall loses.

The exergy losses in the system can be reduced by increasing the capacity of the plant which will in turn reduce the load on the boilers. Process heat integration of the plant can also help to improve the energy utilization and profitability of the system. The analysis also illustrates the fact that exergy balance is a powerful diagnostic tool for energy use optimization.

\section{REFERENCES}

[1] M. Akpan, "The Oil War: Local Vegetable Oil Producers Take Their Case against Importation to the Presidency," 2000. www.newswatchngr.com

[2] L. F. Pellegrini and S. de Oliveira, "Exergy Analysis of Sugarcane Bagasse Gasification,” Energy, Vol. 32, 2007, pp. 314-327.

[3] D. A. Fadare, D. O. Nkpubre, A. O. Oni, A. Falana, M. A. Waheed and O. A. Bamiro, "Energy and Exergy Analyses of Malt Drink Production in Nigeria,” Energy, Vol. 35, No. 12, 2010, pp. 5336-5346. doi:10.1016/j.energy.2010.07.026

[4] E. Sorguven and M. Ozilgen, "Energy Utilization, Carbon Dioxide Emission, and Exergy Loss in Flavored Yogurt Production Process,” Energy, Vol. 40, No. 1, 2012, pp. 214-225. doi:10.1016/j.energy.2012.02.003

[5] M. A. Waheed, S. O. Jekayinfa, J. O. Ojediran and O. E. Imeokparia, "Energetic Analysis of Fruit Juice Processing Operations in Nigeria,” Energy, Vol. 33, 2008, pp. 35-45. doi:10.1016/j.energy.2007.09.001

[6] E. U. Odigboh, "Machines for Crop Production,” In: B. A. Stout, Ed., CIGR Hand-Book of Agricultural Engineering, American Society of Agricultural Engineers, 1998.

[7] R. P. Singh, "Energy Accounting in Food Process Operations,” Food Technology, Vol. 32, No. 4, 1978, pp. 40-46.

[8] M. A. Rosen, "Energy- and Exergy-Based Comparison of Coal-Fired and Nuclear Steam Power Plants,” Exergy, An International Journal, Vol. 1, No. 3, 2001, pp.180-192.

[9] M. Ozilgen and E. Sorgüven, "Energy and Exergy Utilization, and Carbon Dioxide Emission in Vegetable Oil Production," Energy, Vol. 36, No. 10, 2011, pp. $5954-$ 5967. doi:10.1016/j.energy.2011.08.020

[10] E. Rotstein, "Exergy Analysis: A Diagnosis and Heat Integration Tool,” In: R. P. Singh, Ed., Energy in Food Processing, Elsevier, Amsterdam, 1986.

[11] D. A. Fadare, O. A. Bamiro and A. O. Oni, "Energy and Cost Analysis of Organic Fertilizer Production in Nigeria,” Energy, Vol. 35 No. 1, 2010, pp. 332-340. doi:10.1016/j.energy.2009.09.030

[12] I. Dincer and M. A. Rosen, "Exergy, Energy, Environment and Sustainable Development," Elsevier, Amsterdam, 2007.

[13] H. Dalsgard, "Simplification of Process Integration in Medium-Size Industry," Ph.D. Thesis, University of Denmark, Aarhus, 2002. 